\title{
O uso do Facebook como Ferramenta para a Construção Coletiva de uma Proposta Pedagógica
}

\author{
Letícia Paranhos Menna de Oliveira ${ }^{1}$ \\ João Batista Siqueira Harres ${ }^{2}$
}

\begin{abstract}
Resumo:
0 presente artigo aborda 0 uso de uma ferramenta de comunicação para o planejamento coletivo de uma proposta pedagógica. A atividade aqui discutida se refere a interações entre o bioma Pampa (Região Sul do Rio Grande do Sul) e os habitantes desse território. São analisadas as etapas desse planejamento e as conversas em grupo no Facebook. 0 estudo é fruto de uma pesquisa-ação crítica e colaborativa que teve o objetivo de fortalecer a agroecologia na região de cinco assentamentos da Reforma Agrária no município de Herval/RS. A utilização do Facebook como ferramenta de comunicação foi escolhida para contatos instantâneos do grupo. A atividade aqui discutida envolveu estudantes de 1o ao 8o ano, pertencentes a duas escolas do campo que atendem cerca de 300 famílias campesinas, com o tema gerador Bioma Pampa e o Ser Pampiano, embasada em referenciais teóricos da Educação Popular, Ambiental e do Campo. 0 Facebook se mostrou uma ferramenta útil para a conversação necessária ao planejamento pedagógico, em especial quando operada em formato de reuniões on-line, enquanto os educadores residentes em Herval/RS e Porto Alegre/RS estavam conectados em horários previamente combinados. 0 coletivo avalia que, em razão do distanciamento físico, precauções com uma forma de escrita que não gere desentendimentos devem ser pensadas, além de perceberem a facilidade de troca de materiais didáticos pelo ambiente virtual.
\end{abstract}

Palavras-chave: Educação popular. Educação ambiental. Educação do campo. Mídias sociais.

\footnotetext{
1 Mestranda do PPG em Educação em Ciências e Matemática da PUCRS. Bióloga e educadora popular ambiental no Amigos da Terra Brasil. leticiapmo@yahoo.com.br

2 Doutor em Educação, professor da Faculdade de Física da PUCRS e do PPG em Educação em Ciências e Matemática. joao.harres@pucrs.br 


\title{
THE USE OF FACEBOOK AS A TOOL FOR THE COLLECTIVE CONSTRUCTION OF A PEDAGOGICAL PROPOSAL
}

\begin{abstract}
:
This article addresses the collective construction of a pedagogical proposal mediated by the computer, from the resources of group conversation in the social network Facebook. The study is the result of a critical and collaborative action research that had the objective of strengthening of a agroecological process in the region of five settlements of Agrarian Reform in the city of Herval/RS. We emphasize that the use of Facebookas a communication tool was chosen due to the slowness of the Internet in rural areas, and it was the form of communication chosen by the collective. The activity discussed here involved students from 1st to 8 th grade, they belong to two rural schools that attend about 300 peasant families, with the theme of Pampa Biome and To be pampean, based on theoretical references of popular, environmental and agricultural education. The Facebook has proved to be a useful tool for the required communication of the pedagogic planning, especially when it is operated in online meetings format, while educators residents in Herval/RS and Porto Alegre/RS were connected at pre-arranged times. The collective evaluates that due to the physical distance, precautions with a form of writing that does not create misunderstandings should be considered, in addition to perceiving the ease of didactic material exchange by the virtual environment.
\end{abstract}

Keywords: Popular Education. Environmental Education. Agricultural Education. Social Media. 
O desenvolvimento das tecnologias da informação tem gerado novas formas de comunicação, modificando seus comportamentos e ações. Castells (2003, p. 8), pesquisador que estuda as relevâncias das tecnologias para a reorganização da sociedade capitalista, considera que ao final do século 20 houve a conexão de três movimentos que resignificaram a estrutura da sociedade para uma relação baseada em redes, que foram: a economia e a globalização do capital, a produção e o comércio; a liberdade individual e a comunicação como valores proeminentes para a sociedade; e, por fim, a revolução microeletrônica que fez com que evoluíssemos na área da computação e telecomunicação.

Lemos e Lévy (2010, p. 29) propõem que a reestruturação da sociedade, defendida por Castells, seja analisada sob a ótica de três elementos distintos: a informação e comunicação proporcionadas pela estrutura em rede; as relações entre as pessoas em redes sociais; e o enfoque da globalização. Esses autores evidenciam as Tecnologias Digitais de Informação e Comunicação (TDIC) como fundantes de uma nova organização da sociedade, tornando-se necessária a reflexão sobre elas. O termo Tecnologias Digitais de Informação e Comunicação é utilizado para caracterizar tecnologias que façam uso do computador e da Internet como ferramentas indispensáveis. A inclusão da perspectiva "digital" faz referência à possibilidade de criação, modificação e reinvenção em novas mensagens, diferenciando-se de mídias convencionais que reproduzem informações (LÉVY, 1999).

Desde então, novos conceitos, como "Sociedade em rede" (CASTELLS, 1999), "Cultura Digital" (LÉVY, 1999) e "Cultura Midiática" (SANTAELLA, 2003), foram gerados a fim de discutir as repercussões dessas tecnologias nas relações sociais contemporâneas.

Conforme Castells (1999, p. 439), a velocidade com que a internet se difundiu na sociedade foi maior do que outros meios comunicacionais como a televisão ou o rádio: "nos Estados Unidos, o rádio levou trinta anos para chegar a sessenta milhões de pessoas [...] a Internet o fez em apenas três anos após a criação da teia”. Durante a primeira fase, chamada de web 1.0, era possível 
a visualização de dados estáticos de forma simples e sem interação conteúdo/ usuário. Neste momento histórico ocorreram as primeiras trocas por meio do correio eletrônico, conectando milhares de pessoas.

A segunda geração da web, conhecida como web 2.0, trouxe um cenário de maior interação entre seus usuários. Primo (2007) salienta que, a partir de seus recursos,

potencializa-se a livre criação e a organização distribuída de informações compartilhadas através de associações mentais. Nestes casos importa menos a formação especializada de membros individuais. A credibilidade e relevância dos materiais publicados é reconhecida a partir da constante dinâmica de construção e atualização coletiva” (p. 4).

A possibilidade de criação de redes sociais a partir da tecnologia advinda da web 2.0 com ferramentas interativas e de compartilhamentos, facilitou um processo natural da existência humana, que é a de se ligar às pessoas e, portanto, se relacionar em rede na sociedade. Neste contexto, surge o Facebook, que, em agosto de 2015, segundo Zuckerberg, seu criador, conectou 1 bilhão de pessoas em um único dia. O recorde foi comemorado pela página pessoal do fundador que afirmou: "uma entre sete pessoas na Terra usaram o Facebook" (BRITISH..., 2015).

A informação supra, porém, também afirma que seis pessoas de cada sete ainda não estão conectadas. Cabe, portanto, a reflexão sobre as dificuldades que a população rural enfrenta quando o assunto é infraestrutura pública no alcance à internet. Munarin (2014), ao analisar o acesso às tecnologias em zonas rurais brasileiras, salienta as diferenças entre a política pública voltada para o urbano e para o rural, reforçando "a emergência na elaboração de políticas e no cumprimento de metas na disponibilização de acesso à Internet por agências estatais e empresas de telecomunicação que exploram os serviços no Brasil" (p. 82). Castells (2003) converge para essa noção de que os habitantes do interior dos Estados não têm acesso às tecnologias, e, portanto, estão atrasados em relação à comunicação e informação quando comparadas com populações que residem em metrópoles. Nesse sentido, o avanço das tecnologias trouxe consigo mais uma forma de exclusão: a digital. 
O contexto do trabalho aqui exposto é mais um dos muitos pontos praticamente isolados deste país. Assim, o Facebook foi o meio de comunicação utilizado por um grupo de pessoas que reside em Porto Alegre/RS ou Herval/ RS que se propôs a construir uma proposta pedagógica de forma coletiva. $\mathrm{O}$ campo de ação da pesquisa foi a cidade de Herval/RS, situada na metade sul do Rio Grande do Sul. O planejamento da atividade discutido no presente artigo foi pensado para desenvolvimento em duas escolas rurais que atendem as 300 famílias assentadas da Reforma Agrária via Movimento dos Trabalhadores Rurais Sem Terra (MST). Os educadores que elaboraram a proposta são integrantes do Núcleo Amigos da Terra Brasil ${ }^{3}$ (ATBr) e também do Sítio Cultural Ibiekos ${ }^{4}$ (SCI). A partir dessa relação foi elaborado o projeto intitulado Fortalecendo a Soberania Alimentar, Conservando Saberes e Preservando o Bioma Pampa (a partir daqui FSA) ao qual essa pesquisa se vincula. ${ }^{5}$

O projeto parte do entendimento comum de que difundir o conhecimento ancestral é a melhor estratégia para trabalhar na preservação do bioma e na construção da Soberania Alimentar. Não somente os conhecimentos de usos da flora nativa, mas também os de agricultura e pecuária substituídos no processo de apropriação do território pelo agronegócio. ${ }^{6}$ Nesse contexto, o FSA visou a fortalecer o trabalho agroecológico existente na região, com resgate de saberes que fomentem a Autonomia Campesina. Para isso, o coletivo do projeto se propôs a estudar práticas coerentes com esse objetivo a partir de encontros para

${ }^{3} \mathrm{O}$ ATBr é uma organização da sociedade civil com sede em Porto Alegre/RS pertencente à Federação Internacional Friends of the Earth.

${ }^{4}$ O SCI foi fundado em Herval (RS) por duas famílias assentadas em 2002, via MST, no assentamento Tamoios - Vista Alegre -, visando a difundir a permacultura, a agroecologia e propagar saberes políticos, sociais e culturais.

${ }_{5}$ O projeto foi apoiado pela Fundação Luterana de Diaconia por meio do Edital de Justiça Socioambiental, entre agosto/2015 e julho/2016.

${ }^{6}$ Para Fernandes (2008, p. 40-41), os territórios do campesinato e os territórios do agronegócio possuem diferenças desde as relações sociais que estabelecem, manifestando que "o agronegócio organiza seu território para produção de mercadorias, o grupo de camponeses organiza seu território, primeiro, para sua existência, precisando desenvolver todas as dimensões da vida. [...] A mercadoria é a expressão do território do agronegócio". 
trocas de saberes intergeracionais com o Grupo Biodiversidade/Herval (GBio). ${ }^{7}$ Dessa forma, foi possível ampliar o conceito de comunidade escolar para além dos familiares dos educandos e profissionais da escola.

Este artigo reflete sobre o uso da ferramenta de conversa disponível no Facebook como canal de comunicação durante o planejamento coletivo de uma proposta pedagógica relacionada com o Bioma Pampa ${ }^{8}$ e o Ser Pampiano, ${ }^{9}$ desenvolvido ao longo do FSA, que envolveu o uso do Google Earth e a montagem do mapa físico em formato de quebra-cabeça, músicas, filmes e documentários, rodas de conversas e outras dinâmicas pensadas para facilitar um processo de resignificação da identidade campesina pampiana.

\section{Conceitos e Relações entre Educação Popular, do Campo e Ambiental}

Primeiramente se faz necessário referenciar alguns termos que são importantes para o entendimento da proposta. Por exemplo, o conceito de Soberania Alimentar, discutido neste trabalho, vai ao encontro do que defende a Via Campesina: ${ }^{10}$

La soberanía alimentaria es el derecho de cada pueblo a definir sus propias políticas agropecuarias y en materia de alimentación, a proteger y regular la producción agropecuaria nacional y el mercado doméstico a fin de alcanzar metas de desarrollo sustentable, a decidir en qué medida quieren ser autodependientes, a impedir que sus mercados se vean inundados por productos excedentarios de otros países que los vuelcan al mercado internacional me-

7 O GBio é composto por agricultoras e agricultores agroecológicos assentados pela reforma agrária via MST no município de Herval/RS.

8 O Bioma Pampa está situado na metade sul e oeste do Rio Grande do Sul, além de suas extensões para o Uruguai e Argentina. Sua superfície ocupa $178.243 \mathrm{Km}^{2}$ do território brasileiro, sendo a casa de muitas espécies da flora e da fauna nativas, algumas delas encontradas exclusivamente neste ambiente.

9 Escolhemos a expressão "Ser Pampiano" ao invés de "Gaúcho" por remeter não apenas a seres humanos e incluindo a perspectiva também de seres não vivos.

${ }^{10}$ Organização Internacional que reúne movimentos sociais do campo em mais de 70 países. 
diante la práctica del "dumping", ${ }^{11}$ y a darle preferencia a las comunidades locales pescadoras respecto al control del uso y los derechos sobre los recursos acuáticos. La soberanía alimentaria no niega el comercio internacional, más bien defender la opción de formular aquellas políticas y prácticas comerciales que mejor sirvan a los derechos de la población a disponer de métodos y productos alimentarios inocuos, nutritivos y ecológicamente sustentables. La soberanía alimentaria es el derecho de los pueblos, de sus países o Uniones de Estados a definir su política agraria y alimentaria, sin dumping frente a países terceros (VIA CAMPESINA, 1996).

Ao longo das discussões em coletivo também emergiram debates sobre autonomia campesina. Após uma busca em referenciais sobre essa definição, convergimos com Campos (2006), para quem a expressão "autonomia campesina" surge como conquista da luta dos movimentos sociais e manifesta-se das seguintes formas:

a) $\mathrm{Na}$ capacidade do campesinato se tornar sujeito social, com identidade própria, que faz disputa política, não sendo mais representado publicamente por organizações ou pessoas que se comovem com seu sofrimento, mas se representando através de seus movimentos e organizações, que buscam formar lideranças próprias;

b) No fato de o campesinato compreender cada vez mais que as causas das dificuldades de sua vida não são provocadas pela natureza, pela vontade divina, mas pelo funcionamento do capitalismo, em escala local e global;

c) Pela capacidade de ir rompendo com o medo de sair de seu próprio mundo, buscando entender e respeitar a própria diversidade, procurando construir a unidade camponesa, mas se dando conta das diferenças étnicas, religiosas, de gênero. E dentro dos próprios movimentos camponeses surgem cada vez mais movimentos impulsionando o respeito a essas diferenças e com vistas à igualdade de participação;

d) Pela maturidade para perceber que se o capital é globalizado e vem globalmente sufocando os modos de vida camponeses, então [é] preciso construir articulações nacionais e internacionais para lutar contra as políticas públicas

\footnotetext{
${ }^{11}$ Dumping (sem tradução para o português) significa “"a ação ou expediente de pôr à venda produtos a um preço inferior ao do mercado, especialmente no mercado internacional, para se desfazer de excedentes ou para derrotar a concorrência' concorrência".
} 
e privadas que ameaçam a agricultura camponesa, enfrentando instituições poderosas do capital como o Banco Mundial, a Organização Mundial do Comércio e empresas multinacionais (p. 151-152).

Nesse mesmo sentido, a pesquisa se identifica com o termo "sulear", utilizado por Paulo Freire em seu livro Pedagogia da Esperança (1992), como “orientação ou direção". "Sulear" significa o inverso de nortear, no sentido de desconstruir a ideia de que o hemisfério norte seja o "criador" e o hemisfério sul seu "imitador". Também indica a busca pela construção de um saber local, com a postura de quem está de frente para o Cruzeiro do Sul; afinal é a constelação que historicamente guia e orienta os povos do sul. Ainda sobre o conceito de “sulear", evidenciam-se as reflexões de Adams (2008) a respeito da pedagogia de Paulo Freire, em que a terminologia se refere à autonomização e luta pela emancipação dos povos da América do Sul, deixando de ser colonizados, implicando que os próprios povos construam um "outro mundo possível".

O trabalho desenvolvido teve o intuito de resgatar saberes populares regionais com a intenção de valorizar os conhecimentos ancestrais dos campesinos e os seus próprios saberes. Partindo dos saberes compartilhados, realizamos um diálogo sobre "o que mudou na agricultura" e "como isso influencia o meu modo de viver". Assim, suleamos as práticas pedagógicas no intuito de promover discussões sobre a realidade de quem vive no campo.

Na região onde foi desenvolvida a proposta, contornando os assentamentos, o agronegócio avança, afetando de diferentes formas o modo de viver dos agricultores assentados. Alguns perdem o horizonte com plantações de eucalipto, outros o acesso à água pelo uso de agrotóxicos em larga escala (esse, especialmente, utilizado pela monocultura da soja). Por isso, a importância de uma educação que problematize sobre os diferentes paradigmas agrários e que esteja a serviço dos interesses campesinos. Sobre isso, Gohn (2005) ressalta que “o princípio básico adotado pela Educação Popular foi o desenvolvimento de uma ação pedagógica conscientizadora, que deveria atuar sobre o nível cultural das camadas populares, em termos explícitos dos interesses delas" (p. 48). 
Segundo Freire (2005), o oprimido (indivíduo subordinado ao sistema econômico e social que tem sua atuação limitada) é impedido também de viver plenamente sua condição humana. Apenas o conhecimento possibilita sua liberdade e humanização. Tal liberdade oportuniza ao sujeito assumir suas responsabilidades por meio do saber, não mais se omitindo. Esse indivíduo, portanto, passa a criar, questionar, problematizar, construir e atuar no mundo, tendo, assim, condições de transformar sua própria realidade ao desenvolver uma consciência crítica.

Souza (2009) manifesta a importância sobre debater a educação popular no campo, nas escolas e assentamentos rurais, justamente pelo potencial de discussão e mudanças de paradigmas em relação à questão agrária. Neste contexto, o autor (2009) acredita que:

[...] por meio de estratégias dialéticas de formação de produtores tradicionais e assentados, podemos transformar uma proposta conservadora, baseada no difusionismo de informações e na venda do pacote tecnológico, em uma proposta democrática (p. 74).

A busca por autonomia e emancipação dos campesinos, objetivada pelo movimento em prol da Educação Popular e da Educação do Campo, diz respeito não somente à luta pela conquista da terra e pela educação para os trabalhadores da terra, mas também é uma luta pela agroecologia. A Reforma Agrária, neste contexto, é, segundo Da Silva (2012), uma luta agroecológica por:

[...] potencializar a produção de alimentos de forma diversificada e em consonância com o respeito ao bioma que o cerca. [..] ferramenta fundamental de questionamento dessa matriz produtiva centrada no latifúndio, na monocultura de exportação e no uso desenfreado de agroquímicos que destroem a fertilidade da terra, do lençol freático, contaminando alimentos que vêm para a nossa mesa, e, ainda, expulsando os trabalhadores rurais de suas terras [...] (p. 34-35).

É importante salientar que a abordagem teórica e prática do projeto em questão, além de se embasar na Educação Popular e do Campo, faz uso da Educação Ambiental (EA) pela vertente Crítica a partir de autores que não 
consideram a EA como uma prática direcionada ao ensino de ecologia ou com intenções mercadológicas, portanto desvinculada do contexto social. Ao contrário, foram aprofundados estudos em referenciais que se fundamentam no pensamento freiriano, compreendendo a EA em sua perspectiva emancipatória e identificando seu potencial transformador.

Propostas de EA, ancoradas nas ideias de Paulo Freire, possuem no seu centro o debate do resgate histórico do povo brasileiro, de forma a contextualizar os diversos agentes sociais que produziram a realidade ambiental que hoje vivenciamos. Para exemplificar, Loureiro (2005, p. 1.476) atenta para aspectos indissociáveis à prática da EA, com particularidades como:

- busca da realização da autonomia e liberdades humanas em sociedade, redefinindo o modo como nos relacionamos com a nossa espécie, com as demais espécies e com o planeta;

- politização e publicização da problemática ambiental em sua complexidade; convicção de que a participação social e o exercício da cidadania são práticas indissociáveis da Educação Ambiental;

- preocupação concreta em estimular o debate e o diálogo entre ciências e cultura popular, redefinindo objetos de estudo e saberes;

- indissociação no entendimento de processos como: produção e consumo; ética, tecnologia e contexto sócio-histórico; interesses privados e interesses públicos;

- busca de ruptura e transformação dos valores e práticas sociais contrários ao bem-estar público, à equidade e à solidariedade.

Para além da visão crítica do educador em relação às questões ambientais e principalmente sociais, assinaladas anteriormente, apesar de ser fundamental, não garante uma boa prática educativa (GARCÍA; CANO, 2006). Para estes autores, o enfoque deve ser o olhar e as experiências dos educandos sobre o tema. Layrargues e Deboni (2006) convergem com esse pensamento expressando a importância de agir-refletir-agir, para que se possa fugir do "ativismo" e chegar à EA crítica e emancipatória. Ativismo é uma expressão utilizada para 
uma das correntes pedagógicas encontradas na EA, que não atenta para aspectos didáticos, sob pena de empregar métodos transmissivos. Como ressaltam García e Cano (2006):

Para muchos educadores ambientales la modificación de las ideas y de las conductas se consigue informando adecuadamente, transmitiendo sin más las "verdades" por ambientales, como si en las personas que aprenden no hubiera concepciones resistentes al cambio que requieren un tratamiento didáctico mucho más elaborado (p. 118).

Os autores supra entendem que, em virtude da formação inicial de grande parte dos educadores ambientais ter sido nas ciências naturais e exatas, o campo didático desta prática educativa ficou em segundo plano. Assim, sobram discussões sobre o "Ambiental" e faltam sobre "Educação". Ao mesmo tempo em que, existem divergências em relação às tendências teóricas da EA, no âmbito da pedagogia urge discutir sobre os modelos didáticos utilizados. Para García e Cano (2006):

si lo que queremos es un cambio radical del pensamiento y de la conducta de las personas, es decir, un cambio lento, gradual, difícil, a contracorriente de la cultura dominante, tenemos que pensar que tal cambio sólo se puede lograr con estrategias de corte constructivista (p. 119).

Os conceitos e diferentes abordagens da educação até aqui discutidos, foram o aporte teórico do grupo de educadores que se reuniu para a realização do projeto FSA, em uma constante avaliação crítica e coletiva da prática pedagógica, para, dessa forma, atingir coerência entre o que pensamos e o que fazemos em termos educativos. Para Freire (2013):

O próprio discurso teórico, necessário à reflexão crítica, tem de ser de tal modo concreto que quase se confunda com a prática. O seu "distanciamento epistemológico" da prática enquanto objeto de sua análise deve dela “aproximá-lo" ao máximo (p. 40). 


\section{Contextualização}

O Bioma Pampa, situado na região da metade sul do RS, campo de ação da pesquisa, tem sofrido agressões ambientais, como desmatamentos, queimadas e plantio de organismos geneticamente modificados em pequenas e grandes propriedades, acarretando a utilização de agrotóxicos em larga escala. Nos últimos anos houve uma expansão da silvicultura de eucaliptos, alterando ainda mais o ambiente natural (BINKOWSKI, 2009). Percebe-se também que as alterações da paisagem não afetam apenas a qualidade ambiental, pois o avanço do agronegócio é preocupante pelos problemas sociais que acarretam:

Vê-se que a engenhosidade do capital no campo via agronegócio ganha expressividade no Brasil, sendo promotora de desigualdade, e a sua expansão promove a redução de alimentos, gerando uma crise e repercutindo, entre outras questões, na impossibilidade da construção da Soberania Alimentar (SANTOS, 2012, p. 92).

Em razão dessas dificuldades, a cada ano aumenta o número de famílias que abandonam o campo (SANTOS, 2012). O saber popular herdado dos ancestrais, no entanto, persiste, mantendo culturas como a socialização de sementes, mudas, conhecimentos sobre a utilização de plantas nativas, entre outras, fatos que demonstram ainda haver uma valorização desse saber por parte dos nativos e também por parte daqueles que migraram para centros urbanos ou rurais, como é o caso dos assentamentos.

Os obstáculos encontrados pelos agricultores no Estado do Rio Grande do Sul, pela falta de possibilidades em gerar renda e garantir qualidade de vida, têm feito com que os interesses das empresas de celulose, biotecnologia e mineração sobreponham as relações do homem com a natureza e, aos poucos, tornam a agricultura dependente de processos industriais e voltada apenas para a geração de lucro.

Suertegaray e Morelli (2011, p. 16), ao analisarem a monopolização territorial no Rio Grande do Sul por corporações de monocultura de eucalipto, identificaram que existe "um projeto a favor das empresas e do capital, outro a 
favor dos movimentos sócio-ambientais vinculados à diversificação dos cultivos e preservação". Entre os conflitos existentes dessa ocupação por empresas madeireiras do hemisfério Norte, principalmente no Sul da América do Sul, está:

Indicativo de Investimentos e liberação de recursos públicos às empresas (assessoria técnica de órgãos públicos, renúncia fiscal, financiamentos); Denúncia de que áreas amplas ocupadas pelas plantações, modificam a paisagem, gerando pouca ou nenhuma renda à população local; Explicitação de danos ambientais relacionados à monocultura e à espécie escolhida, tais como contaminação dos recursos hídricos por pesticidas, diminuição da biodiversidade, contaminação do solo, impacto negativo no ecossistema local; extinção do bioma Pampa e problemas de saúde na população local; Uso de transgenia: monopólio da tecnologia; ocupação do território com riscos sócio-ambientais; Intensificação da concentração de terras por um setor econômico (SUERTEGARAY; MORELLI, 2011, p. 16).

Em contraponto ao modelo de desenvolvimento agrário do agronegócio, a agroecologia caminha em favor da cultura da vida, da preservação dos bens comuns e do empoderamento dos campesinos. Os coletivos que se envolveram nesta proposta, entendem que dentro deste contexto de financeirização do território, o resgate dos saberes populares é uma estratégia para o fortalecimento da comunidade, ressaltando a importância da inserção desse tema para a escola do campo. Entendendo também como imprescindível o trabalho em rede para a articulação da agroecologia e do desenvolvimento da proposta pedagógica, é que se planejou a interação por meio da Internet, por facilitar a comunicação dos diferentes atores que se envolveram no projeto FSA.

Ainda discutindo a conjuntura, é notável que as escolas do campo, desde 1930, possuem políticas de escolarização urbano-centradas que incentivam os habitantes do campo a "incluir-se" na cidade, ao mesmo tempo em que promovem um afastamento de seus próprios contextos (CALDART, 2010). Por isso, é importante discutir a incorporação das tecnologias digitais de forma que proporcionem acesso ao "maior latifúndio"12 do mundo e, principalmente, estabeleçam "espaços de comunicação e criação de redes que fortaleçam as

\footnotetext{
${ }^{12}$ Para Munarim (2014, p. 81) a Internet representa hoje o "maior latifúndio" do mundo.
} 
reivindicações dos sujeitos do campo" (MUNARIM, 2014, p. 172). Com a finalidade de proporcionar a discussão sobre os problemas globais com o olhar de quem vive no campo e acredita nessa forma de vida, é que a conversa em grupo no ambiente virtual foi criada, entendendo as infinitas possibilidades na relação entre campesinos, educadores, educandos, familiares e professores no planejamento de uma proposta pedagógica voltada para o resgate dos saberes e fortalecimento da agroecologia.

\section{Metodologia do Projeto: pesquisa-ação}

A metodologia do projeto, como contexto da discussão do uso de mídias para seu planejamento, está ancorada na pesquisa-ação (PA) crítica e colaborativa, por que a crítica e o desejo de transformação da realidade foram construídos igualmente por todos os sujeitos envolvidos, bem como a elaboração do projeto FSA e seu desenvolvimento (FRANCO, 2005). Nessa perspectiva, a autora assume também o papel de participante das ações, como educadora do projeto FSA:

Pode-se observar que as origens da pesquisa-ação com Lewin identificam uma investigação que caminhe na direção da transformação de uma realidade, implicada diretamente na participação dos sujeitos que estão envolvidos no processo, cabendo ao pesquisador assumir os dois papéis, de pesquisador e de participante, e ainda sinalizando para a necessária emergência dialógica da consciência dos sujeitos na direção de mudança de percepção e de comportamento (2005, p. 487).

Entre os objetivos da PA está a busca por ações práticas em situações concretas, intervindo na realidade e buscando sua transformação. Por isso, ressaltamos a sua similaridade com a perspectiva emancipatória da educação. Nesse mesmo sentido, Le Boterf (1999, p. 73) afirma: 
PA consiste num processo educativo. Ao participar do próprio processo da pesquisa e da discussão permanente dos resultados obtidos, os pesquisadores podem adquirir um conhecimento mais objetivo de sua situação, assim como analisar com maior precisão os seus problemas, descobrir os recursos de que dispõem e formular ações pertinentes.

Os participantes do Coletivo Educador-Pesquisador (CEP) atuam nos movimentos ambientais e sociais. Por isso, o projeto possui caráter de comprometimento sociopolítico em prol de uma causa, neste caso, a causa das famílias campesinas na busca da valorização dos saberes regionais e fortalecimento da soberania alimentar. Assim, vinculam-se com as posições defendidas por Paulo Freire (1986) e Delorme (1982), pertencentes à corrente da PA denominada “movimientos comunitarios", e que, conforme salienta Serrano (1990, p. 40), contribuem à metodologia, no sentido em que sua integração "se mueve a un nível de teoría política, ligada de manera diferente al proyecto político dominante”.

Para o planejamento das atividades, os integrantes das organizações que formaram o CEP, por não residirem na mesma cidade, optaram pelo diálogo on-line. Como já mencionado, porém, o serviço de internet em Herval, em especial nos assentamentos, é lento, impedindo o uso, por exemplo do skype. ${ }^{13}$ Além disso, outros canais de comunicação, como o conhecido whatsapp ${ }^{14}$ ou telegram ${ }^{15}$ não eram compatíveis com a realidade da totalidade dos membros do coletivo, pela falta de telefones celulares adequados ao uso dessas tecnologias. Dessa forma, a Rede Social Facebook se tornou a única ferramenta verdadeiramente acessível às condições da equipe.

\footnotetext{
${ }^{13}$ O Skype foi lançado em 2003 e, desde 2011, pertence à Microsoft. Trata-se de um aplicativo que proporciona comunicação de voz e vídeo por meio da Internet.

${ }^{14}$ O Whatsapp é um aplicativo de mensagens instantâneas, criado em 2009, disponível para smartphones e com serviço de compartilhamento de vídeos, mensagens de texto e voz e arquivos.

${ }^{15}$ Fundado em 2013, o Telegram, é um aplicativo que oferece troca de mensagens instantâneas para usuários de smartphones e tablets (Android, iOS, Windows Phone, entre outros) e para computadores (Windows, Linux, entre outros) e pode ser usado também como aplicação da web.
} 
Primo (2007, p. 4) destaca que ferramentas da internet, como a escolhida pelas educadoras, possuem certa “arquitetura de participação", oferecendo ferramentas com características que facilitam não só somente a comunicação, mas também “a gestão coletiva do trabalho comum”. Boyd e Heer (2006) destacam que a conversação que acontece por meio de um computador, muitas vezes é igualada à conversação ao vivo, de forma oral.

\section{Diálogos no Facebook: a mediação do processo de planejamento coletivo}

Os instrumentos utilizados ao longo do projeto para organizar as reflexões da pesquisa, e discutidos a seguir, foram: os registros da conversa de grupo no Facebook; os áudios dos encontros presenciais; a observação participante; filmagens dos sujeitos envolvidos no projeto FSA (em especial, educadores e familiares); diário de bordo de cada integrante do CEP.

O grupo de conversa via Facebook foi criado em abril de 2015 para facilitar a elaboração do projeto FSA. Neste primeiro momento estavam engajadas duas agricultoras do SCI e duas militantes do ATBr, que ficaram responsáveis pela elaboração do projeto.

Os diálogos anteriores à construção de metodologias proporcionaram trocas sobre perspectivas pedagógicas, para que os participantes se conhecessem enquanto educadores, uma vez que este foi o primeiro trabalho no campo da educação no qual esse grupo envolveu-se. O reconhecimento da caminhada de cada um foi importante para que as capacidades de cada integrante fossem percebidas por todos e, assim, acarretar em um melhor planejamento das ações. Sobre as trajetórias diferentes que se encontraram e desenvolveram um projeto conjunto, destaca-se a avaliação de uma das educadoras:

O que nos une é o que temos em comum, não o que temos de diferente, o que temos de diferente nos alimenta a experimentar o novo, esse é o grande lance da diversidade. (Retirado de Conversa em Grupo - Facebook. Setembro, 2015).

Após a aprovação da proposta em edital, no mês de julho o grupo aumentou. Ao canal de comunicação agregaram-se quatro filhos adolescentes das famílias que compõem o SCI e outras três pessoas do ATBr. Após meses de 
conversação virtual foi realizado um encontro ao vivo no qual foram definidos alguns princípios para a construção da proposta. Por exemplo, a intenção de propiciar encontros com o GBio, com a identificação da potencialidade da troca de saberes intergeracionais entre os griôs ${ }^{16}$ e a juventude rural. Os integrantes do GBio, em sua maior parte, não compõem a "comunidade escolar". Esta se limita aos familiares dos educandos e trabalhadores da escola. Além disso, considerando que os saberes campesinos são culturalmente compartilhados de forma oral, os encontros foram tomados como um espaço de valorização desses saberes, inclusive dentro da escola.

Sobre o Bioma Pampa e o Ser Pampieano foi discutida a importância de ser estabelecido um diálogo que demonstrasse, a partir da fala dos educandos, o quanto "a pampa só existe por causa do gaúcho e o gaúcho só existe por causa da pampa, ${ }^{17}$ " apresentando reflexões sobre o quanto o ambiente e o ser humano estão interligados e interagem entre si. As educadoras de Herval destacaram o desconhecimento do Google Earth na comunidade, indicando como válida a utilização para explorarem a ferramenta, porém, na escola não havia computadores (em funcionamento) ou internet à disposição. Por isso, as imagens da região foram gravadas para futura utilização de forma off-line por um notebook, cedido por uma das educadoras, e o data-show da escola.

Após o encontro ao vivo, houve um retorno à conversação on-line. A ação prática foi sistematizada para este primeiro encontro do FSA, que já possuía o tema gerador Bioma pampa e o Ser Pampieano. Aqui se destaca a sistematização sobre as atividades que estavam sendo propostas elaborada por uma das educadoras de Herval/RS:

A proposta foi elaborada com base no pensamento sobre a importância da descoberta; não dar a resposta, proporcionar a percepção por parte das crianças. Até porque as respostas não estão prontas, não existe certo e

\footnotetext{
${ }^{16}$ Griôs são considerados anciões que guardam a memória dos saberes populares, como, por exemplo, o manejo, a conservação e a propagação de sementes crioulas de uma determinada região. A pedagogia dos Griôs tem como principal metodologia a oralidade, ou seja, a contação de histórias sobre as origens das coisas e sua trajetória (FONTENELE, 2011. p. 24).

${ }^{17}$ Expressão popularmente conhecida no Rio Grande do Sul.
} 
errado quando falamos dos nossos saberes. Por isso vamos partir das suas realidades (apresentações, relatos sobre o que fazem e a nossa proposta do projeto com eles), transitando sobre o ambiente onde vivemos (o bioma Pampa), e levando a "pensar sobre a origem dos saberes" (cultura imposta, cultura ancestral...), será possível criar uma base consciente e crítica, o que permitirá que no próximo encontro (com o retorno da tarefa observada e construída junto com as famílias / com a presença do grupo de biodiversidade / com relatos filmados de griôs) possamos vir a abordar o tema "importância da produção de alimento, cuidado com o ambiente, revolução verde..." e elaborar uma forma pedagógica de descobrimento deles sobre o que é soberania, e então, a partir daí, frisar a importância da soberania alimentar. Com certeza já ouviram falar sobre, mas não sei se compreendem o que é soberania, será uma palavra alienígena, sem pertença, uma resposta pronta. *Provavelmente haverá diferenças entre as turmas, de compreensão, de desenvolvimento do raciocínio, de atenção sobre os temas propostos, o que poderá ser analisado após o primeiro encontro (Retirado de Conversa em Grupo - Facebook. Setembro, 2015).

Com a proximidade do primeiro dia de atividades a necessidade do diálogo era mais intensa. Nesse contexto, percebeu-se que houve alguns problemas na comunicação: demoras nas respostas; dificuldade de acompanhar o grupo a todo o momento; conversas dispersas; falta de acordos e entendimentos coletivos; descuido na escrita, desrespeitando a falta de entonação e podendo gerar desentendimentos. Esses pontos foram avaliados pelos integrantes no próprio ambiente do Facebook e o primeiro encaminhamento foi de estabelecer uma comunicação via e-mail, que se demonstrou inacessível para alguns integrantes, tendo pequena adesão. Dessa forma, coletivamente, optou-se por realizar reuniões on-line, indicando dias que cada um estava disponível e com acesso à internet, preferencialmente reunindo as pessoas de cada município para facilitar ainda mais a comunicação.

Outro acordo coletivo que facilitou o trabalho mediado pelo computador foi a construção de pontos de pauta anteriores ao encontro on-line, de forma a organizar a discussão. Essa nova conformação de conversa não interferiu na dinamicidade ou espontaneidade natural oferecida pelas redes sociais, pois os integrantes não deixaram de utilizar o canal em outros momentos além da 
conversa on-line, que se propunha ser sempre para encaminhamento das ações. Além disso, o roteiro de cada encontro era construído semanalmente por todos, refletindo desde as angústias individuais até as demandas concretas do projeto.

O primeiro momento de discussão em formato on-line no Facebook contou com cinco integrantes do SCI, conectados por um computador e um telefone celular, e quatro integrantes do $\mathrm{ATBr}$, mediados pelo computador na sede da organização. Ao iniciar o encontro on-line, uma das educadoras de Herval se manifestou sobre a primeira atividade, indicando algumas possibilidades e estratégias que havia pensado:

Considerando que trabalharemos com as turmas durante todo o período (toda manhã ou toda tarde) pensei em dividir o tempo em ambiente exterior e interior: Primeira parte do encontro: ao ar livre, no campo de futebol gramado da vila para apresentação de todos (nome, o que fazem além de estudar, o que gostam de fazer) (+-40 min) - nós falarmos sobre o projeto, como foi o caminho pra estarmos ali hoje. - lançar perguntas: "O que sabes sobre o Pampa? Que animais do Pampa tu conheces? E plantas?" (mais ou menos $40 \mathrm{mim}$ ). Segunda parte, de volta à escola, na sala, cadeiras em círculo - vídeo GoogleEarth-pergunta: "O que temos em comum com outros povos?", "Qual a importância do nosso bioma no planeta?” Enfatizar, a partir da fala deles, a importância do Pampa para inúmeras espécies de vidas, inclusive a nossa (quanto tempo?) RECREIO (lanche das crianças). Terceira parte, - "O que é cultura?" "O que mudou, desde o tempo dos nossos avós até hoje?" - mapa do bioma a ser preenchido por el@s (essa partenão tenho claro) *foi falado na nossa reunião sobre: forma de produção, flora e fauna nativa, benzedura, alimentos, relação com a Lua (acho que isto não foi falado), etc. Teria que haver uma pergunta que englobasse todos esses temas pra continuarmos a preencher o mapa no próximo encontro. Última parte, despedida, agradecimentos, comprometimento mútuo (criar este momento?). É possível apresentar um mapa do Pampa (c/Uruguai, e Argentina) de 50 anos atrás e um mapa atual, pra termos uma ideia da dimensão da nossa interferência? "como nossos ancestrais trabalhavam e como é hoje" (Retirado de Conversa em Grupo - Facebook. Setembro, 2015). 
Nos encontros que se seguiram, foram definidos ainda dois filmes para facilitar a discussão neste primeiro encontro. Para as séries iniciais: Pateta, $o$ Gaúcho, ${ }^{18}$ da Disney, com 8 minutos de estória. Este filme foi escolhido por apresentar uma caricatura da tradição cultural do Estado, e, então, propiciaria uma leitura real de como é o ser que vive no Pampa, algo diferente do que é apresentado no filme. Para as séries finais do Ensino Fundamental, foi definido que seriam mostrados alguns trechos do documentário produzido pela Empresa de Assistência Técnica e Extensão Rural do Governo do Estado do Rio Grande do Sul (Emater-RS) no projeto RS Biodiversidade, denominado Bioma Pampa. O documentário possui 15 minutos de duração, mas foram apresentados cerca de 8 minutos. ${ }^{19} \mathrm{O}$ documentário localiza o bioma e reforça a importância da fauna e da flora nativa, associando-o com a figura e a história do gaúcho.

Os planejamentos que necessitavam de acesso à Internet para busca de materiais, como o filme, exemplificado acima, mesmo com os educadores de Herval não tendo acesso, poderiam ser descritos, a partir da sinopse, no ambiente do Facebook. Semanalmente era feito o download dos materiais necessários de forma que todo o grupo podia assistir as opções discutidas.

A maior dificuldade encontrada foi a formulação do trajeto no Google Earth, pois quem tem o maior conhecimento da região não tinha acesso à internet para realizar as buscas. As tentativas, mesmo no formato on-line da conversa de Facebook, não fluíam. Por isso utilizamos o transporte público que, uma vez por semana, atende às comunidades que vivem nos assentamentos de Herval para chegar até a cidade e utilizar uma lan house, aonde, com o acesso à Internet, foi possível preparar o material utilizado usado no Earth. A partir do compartilhamento on-line, em POA foram gravados os dados no notebook e conduzidos à cidade de Herval. Esse empecilho com o uso da Internet no assentamento coincidiu com uma das muitas semanas em que faltou transporte escolar em razão das chuvas e do péssimo estado das estradas, portanto não houve atraso no início da atividade.

${ }_{18}$ Disponível em: <https://www.youtube.com/watch?v=gD6r5Wqf2Jc>. Acesso em: 29 nov. 2016.

${ }^{19}$ Disponível em: <https://www.youtube.com/watch?v=QxG-zMl3IVI>. Acesso em: 29 nov. 2016. 
O trajeto inicia com o Bioma Pampa visto sem a separação por países, discutindo as nossas semelhanças com outros povos, e, ao aproximar, destaca em amarelo, o caminho que faz o ônibus escolar (Figura 1). O trajeto compreende desde a casa do educando que reside mais longe, iniciando sua jornada às $6 \mathrm{~h} 15 \mathrm{~min}$ para chegar às $8 \mathrm{~h} 40 \mathrm{~min}$, percorrendo $30 \mathrm{~km}^{2}$ até a escola. Em um dos encontros, posterior ao compartilhamento dos pontos no Earth, uma das educadoras sugeriu que também fossem utilizadas as imagens do Google para a construção de um mapa físico, em formato de quebra-cabeça. Para tanto, foram impressas cerca de 60 páginas em A4 com fragmentos da imagem abaixo, para posterior montagem. Neste mapa seriam alocados os desenhos das casas e da produção de cada família.

Figura 1 - Imagem do Google Earth compreendendo o percurso do ônibus escolar até a escola

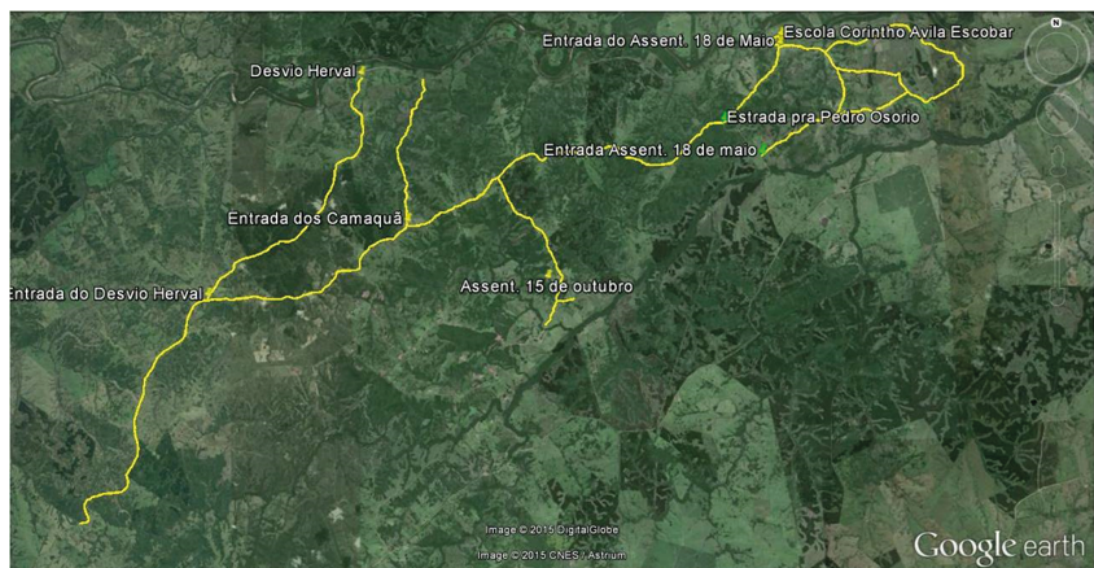

O coletivo ainda estava em busca de uma música que favorecesse a percepção de um ambiente agradável para essa atividade inaugural. Durante a discussão alguns cantores que foram citados subsidiaram a conversa sobre a figura do gaúcho a ser trabalhada; uma das educadoras suleou o debate:

O nosso projeto consiste em fortalecer, aos que já tem, e criar, aos que não tem, uma identidade pampiana. Escrevemos no projeto que acreditamos que a preservação do seu lugar está diretamente ligada ao quanto seu povo 
conhece, usa e valoriza o seu território. Porém, existe um estereótipo de gaúcho pampiano, que é o estancieiro e o peão, um não existe sem o outro e os dois não existem sem o latifúndio. É a identidade que se canta na maioria das milongas e versos, é a que passa na televisão, a que o Movimento Tradicionalista Gaúcho cultua, ajudando o Estado a cumprir o seu papel. Acredito que não é esta identidade que queremos construir! Acredito que buscamos a identidade do gaúcho, mestiço, miscigenado de raças, crenças e culturas, que se criou no clima cheio de extremos do solo pampiano, onde as plantas são mais densas, crescem lentas e com mais fibra, onde o tempo severo deixa a fruta mais doce. Lugar onde criam de tudo e tem farmácia no mato e no jardim. O gaúcho que ama o cavalo como parceiro, amigo, e não como servente. $O$ que coloca nome nas vacas, e adora amamentar um guacho. [Guacho: filhote de cavalo ou ovelha que, por algum motivo, é abandonado pela mãe ou retirado dela, por isso cresce na volta da casa com cuidados especiais]. Ah, se existisse um super-herói gaúcho, sua arma secreta seria um pedaço de arame. E ele usaria bota e bombacha porque é confortável e não porque é a moda ou é setembro... (Retirado de Conversa em Grupo - Facebook. Setembro, 2015).

Apesar de o coletivo ter uma variedade de músicas que poderia ser utilizada como disparadora, algo deveria ser levado em consideração, principalmente em um primeiro encontro: a preferência musical dos educandos. A escolha foi uma sugestão de um dos adolescentes que estudava na escola e fazia parte do CEP. Eram cantores que faziam reverência à cultura mineira, apesar de soar estranho em um primeiro momento, afinal a proposta era valorizar a cultura pampiana. A partir do debate emergiu a ideia de construir uma paródia musical com os educandos, contemplando, assim, a opinião de todos. Além da estratégia da paródia, combinamos utilizar diferentes canções nos intervalos das atividades em geral, aproveitando a inclinação à integridade provocada pela arte.

O planejamento ao final da discussão foi definido da seguinte maneira:

$\left.1^{\circ}\right)$ roda de apresentação (nome, saberes e fazeres da lida diária que preferem); conversa sobre o projeto e o primeiro dia de atividades;

$2^{\circ}$ ) apresentação dos filmes específicos para cada série; problematização sobre quem é o Gaúcho? Como ele é? O que gosta de fazer? Como vive a vida? Qual a relação do Gaúcho com o Pampa? O que tem na pampa? Bichos e plantas? 
$3^{\circ}$ ) “quem já ouviu falar sobre o Google Earth?": Navegação off-line no software, anotação das perguntas e problematizações para aprofundamento e valorização das falas. Nós podemos questionar: "O que temos em comum com outros povos?", "Qual a importância do nosso bioma no planeta?", "O que é cultura?", "O que mudou, desde o tempo dos nossos avós até hoje?". Identificação do trajeto das casas e do entorno;

$4^{\circ}$ ) montagem do mapa físico, utilizando o computador e o conhecimento sobre o próprio território como referencial;

$5^{\circ}$ ) finalização com uma paródia da música "Vida Boa", interpretada por Victor e Léo a partir da composição de Victor Chaves e bastante escutada entre os jovens, seguida da pergunta geradora: "Se o Victor e Léo fossem gaúchos, como ficaria a música?".

A intenção inicial era de que o GBio e os familiares dos educandos incidissem no encontro. O único transporte disponível, porém é o que leva os educandos e não haveria espaço para que outros membros da comunidade chegassem até a escola. Após esse momento de construção no CEP, o planejamento descrito anteriormente foi compartilhado em outra conversa em grupo criada na Rede Social com os professores da escola, de forma a oportunizar que eles pudessem agregar propostas com a intenção de facilitar suas participações ativas durante a atividade.

\section{Considerações Finais}

Levando em consideração que a escola não possuía telefone,$^{20} \mathrm{o}$ diálogo pela Internet se tornou o único meio de comunicação fora os encontros presenciais. Por falta de transporte escolar, diversas vezes as aulas foram canceladas. Pela rede os professores avisavam sobre a logística e empecilhos que alteras-

\footnotetext{
${ }^{20} \mathrm{O}$ que, infelizmente, não é exclusividade da escola que nos referimos neste artigo, como salienta Munarim (2014, p. 95), "a taxa de estabelecimentos sem energia elétrica é de 15\% (11.413 escolas)", além dos números relacionados à água e saneamento básico, tornando a discussão sobre Internet algo constrangedor.
} 
sem as combinações. A conversa no Facebook com os professores da escola que não integraram o CEP favoreceu o diálogo sobre o projeto, apesar de não estar presente a totalidade dos docentes. A rede social oportunizou a difusão de materiais didáticos e permitiu o compartilhamento sobre as metodologias previamente pensadas pelo CEP. A conversação mediada pelo computador, porém, não avançou no sentido da construção coletiva da proposta, tornando-se um meio para uma comunicação mais direta e objetiva, mas não com trocas reflexivas. A comunicação fluída esteve concentrada no estabelecimento de uma agenda comum com aqueles educadores que aderiram à proposta, para, então, nos integrarmos ao vivo.

É notável que o avanço tecnológico voltado para a conectividade à Internet ainda não se desenvolveu neste ponto do mapa brasileiro, porém a juventude rural anseia pela oportunidade ao seu acesso. Exemplo disso são as listas de filmes, vídeos, músicas entre outros materiais que eram "encomendados" de Porto Alegre (POA). Os adolescentes procuram a conexão com o mundo para além do município de Herval, por isso essa afinidade com as redes sociais foi aproveitada para facilitar o processo de inclusão deles no projeto como um todo.

Alguns dos integrantes adultos que viviam em POA não conheciam pessoalmente os jovens da família anteriormente ao projeto FSA, ou seja, antes mesmo de os participantes darem as mãos, já estava ocorrendo uma socialização aos moldes do mundo virtual. A potência de poder trocar impressões durante o planejamento com quatro adolescentes, que aos poucos se sentiram parte do CEP, interferiu durante todo o percurso e qualificou a proposta. Um dos pontos que auxiliou esse acontecimento é a horizontalidade da ferramenta, sendo um espaço em que qualquer um, a qualquer momento, pode se manifestar; e isso ocorreu devido apor que todos os membros da família foram adicionados na conversa. ${ }^{21}$

Para o CEP, o Facebook, aliado aos encontros ao vivo, serviu como ferramenta de diálogo fundamental ao planejamento pedagógico. A experimentação do ambiente permitiu que todos percebessem quais eram as dificuldades para a construção coletiva sem a proximidade física. Superados esses obstáculos, foi

\footnotetext{
${ }^{21}$ Aqui nos referimos à conversa do CEP, na qual participavam integrantes do SCI e do NAT.
} 
possível aprender com o outro, respeitar opiniões divergentes, buscar consensos e esgotar os dilemas para estar mais bem preparado no momento da ação pedagógica.

Entre os aprendizados, em relação ao uso do espaço para esse fim, está a conclusão de que o formato de encontros on-line é mais funcional e impede desentendimentos entre os integrantes, em especial quando o assunto envolver decisões que competem a todos opinar. Também destacamos sua facilidade para o compartilhamento de materiais didáticos enquanto acontece a formulação da proposta. Além disso, por armazenar todos os diálogos, exerce o papel de diário das ideias e acordos construídos ao longo do tempo.

Por fim, cabe a reflexão de que tanto a pesquisa-ação, quanto o projeto FSA se propõem a fortalecer redes e sujeitos empenhados na construção da agroecologia, em um esforço coletivo de se resgatar a autonomia e o bem-viver campesino. Nesse sentido, a principal rede social da atualidade foi um meio para inspiração e reflexão do grupo, avançando no sentido de uma educação ambiental crítica, popular, com respeito aos saberes camponeses, e, sobretudo, voltada para a construção e não reprodução de conhecimentos.

Esse foi o primeiro planejamento do projeto FSA, após a realização da atividade. $\mathrm{O}$ ambiente virtual também foi meio para a reflexão inerente à prática educativa, e necessária para o seguimento da proposta.

\section{Referências}

ADAMS, T. Sulear (verbete). In: STRECK, D. R.; REDIN, E.; ZITKOSKI, J. (Org.). Dicionário Paulo Freire. 2. ed. Belo Horizonte: Autêntica, 2008. p. 396-398.

BINKOWSKI, P. Conflitos ambientais e significados sociais em torno da expansão da silvicultura de eucalipto na "metade sul” do Rio Grande do Sul. 2009, 208f. Dissertação (Mestrado em Desenvolvimento Rural) - Universidade Federal do Rio Grande do Sul, Faculdade de Ciências Econômicas, Programa de Pós-Graduação em Desenvolvimento Rural, Porto Alegre, 2009. Disponível em: <www.lume.ufrgs.br/handle/10183/22662>. Acesso em: 15 set. 2015. 
BOYD, D.; HEER, J. Profiles as conversation: networked identity performance on friendster. In: HAWAII INTERNATIONAL CONFERENCE ON SYSTEM SCIENCES (HICSS-39). Persistent Conversation Track. Kauai, 2006. Atas ... IEEE Computer Society, 2006. Disponível em: <http://www.danah.org/papers/HICSS2006.pdf>. Acesso em: 25 out. 2016.

BRITISH BROADCASTING CORPORATION (BBC). Pela $1^{\text {a }}$ vez Facebook tem mais de 1 bilhão de usuários em um único dia. 2015. Disponível em: <http://bbc.portuguese/ noticias/2015/08/150828_facebook_recorde_lab>.

CALDART, R. S. A educação do campo e a perspectiva de transformação da forma escolar. In: MUNARIM, A. et al. (Org.). Educação do campo: reflexões e perspectivas. Florianópolis: Insular, 2010. p. 145-188.

CAMPOS, C. S. S. Campesinato autônomo: uma nova tendência gestada pelos movimentos sociais do campo. Revista Lutas \& Resistências, Londrina, v.1, set. 2006.

CASTELLS, M. Sociedade em rede. 6. ed. São Paulo: Paz e Terra, 1999.

. A galáxia da internet: reflexões sobre a internet, os negócios e a sociedade. Trad. Maria Luiza Borges. Revisão Paulo Vaz. Rio de Janeiro: Zahar, 2003.

DA SILVA, M. A. B. R. Educação do campo e agroecologia: continuidades e rupturas na história do assentamento Vereda II - Padre Bernardo, GO. 2012. Dissertação (Mestrado em Educação Ambiental e Educação do Campo) - Universidade de Brasília, 2012. Disponível em: <http://www.mstemdados.org/sites/default/files/2012_MarcoAntonioBarattoRibeirodaSilva.pdf>. Acesso em: 8 nov. 2016.

DELORME, C. De la animación pedagógica a la investigación-acción. Perspectiva para la inovación escolar. Madrid: Narcea, 1982.

FERNANDES, B. M. Educação do campo e território camponês no Brasil. In: SANTOS, C. A. (Org.). Educação do campo: campo - políticas públicas - educação. Brasília: Incra MDA, 2008. p. 39-66.

FONTENELE, I. S. Pedagogia do griô: customizando experiências de vidas e culturas educacionais. 2011. 185f. Dissertação (Mestrado em Educação) - Universidade Federal do Ceará, Faculdade de Educação, Programa de Pós-Graduação em Educação Brasileira, Fortaleza, 2011. Disponível em: <www.repositorio.ufc.br/handle/riufc/7297>. Acesso em: 2 set. 2016.

FRANCO, M. A. S. Pedagogia da pesquisa-ação. Educação e pesquisa, São Paulo, v. 31, n. 3, p. 483-502, set./dez. 2005.

FREIRE, P. Criando métodos de pesquisa alternativa: aprendendo a fazê-la melhor através da ação. In: BRANDÃO, C. (Org.). Pesquisa participante. 6. ed. São Paulo: Ed. Brasiliense, 1986. p. 34-41. 
FREIRE, P. Pedagogia da esperança: um reencontro com a pedagogia do oprimido. 8 . ed. Rio de Janeiro: Paz e Terra, 1992.

Pedagogia da autonomia: saberes necessários à prática educativa. 47. ed. Rio de Janeiro: Paz e Terra, 2013.

Pedagogia do oprimido. 42. ed. Rio de Janeiro: Paz e Terra, 2005.

GARCÍA, J. E.; CANO, M. I. Como nos puede ayudar la perspectiva constructivista a construir conocimiento en educación ambiental? Revista Iberoamericana de Educación, n. 41, p. 117-131, 2006.

GOHN, M. G. M. Movimentos sociais e educação. 6. ed. São Paulo: Cortez, 2005.

LAYRARGUES, P.; DEBONI, F. Conexões. In: BRASIL. Juventude, cidadania e meio ambiente: subsídios para elaboração de políticas públicas (Cap. 4). Brasília: Unesco Órgão Gestor da Política Nacional de Educação Ambiental; Ministério do Meio Ambiente; Ministério da Educação, 2006. p. 191-201.

LE BOTERF, G. Pesquisa participante: propostas e reflexões metodológicas. In: BRANDÃO, C. R. (Org.). Repensando a pesquisa participante. São Paulo: Brasiliense, 1999.

LEMOS, A.; LÉVY, P. O futuro da internet: em direção a uma ciberdemocracia planetária. São Paulo: Paulus, 2010.

LÉVY, P. Cibercultura. Trad. Carlos Irineu da Costa. São Paulo: Ed. 34, 1999.

LOUREIRO, C. F. B. Complexidade e dialética: contribuições à práxis política e emancipatória em educação ambiental. Revista Educação \&. Sociedade, Campinas, v. 26, n. 93, p. 1.473-1.494, set./dez. 2005. Disponível em: <http://www.cedes.unicamp.br>. Acesso em: 4 jul. 2016.

MUNARIN, I. As tecnologias digitais nas escolas do campo: contexto, desafios e possibilidades. 2014, 183p. Tese (Doutorado) - UFSC. 2014.

PRIMO, A. O aspecto relacional das interações na WEB 2.0. E-Compós, Brasília, v. 9, p. 1-21, 2007.

SANTAELLA, L. Comunicação ubíqua: repercussões na cultura e na educação. São Paulo: Paulus, 2003.

SANTOS, R. M. Se planta e se colhe nesse sertão: resistência e permanência da autonomia camponesa e as estratégias do MPA (Movimento dos Pequenos Agricultores) nas contradições do projeto da soberania alimentar. 2012. 252 f. Dissertação (Mestrado em Geografia) - Universidade Federal de Sergipe, 2012.

SERRANO, M. G. P. Investigación-acción: aplicaciones al campo social y educativo. Madrid: Dykinson, 1990. 
SOUZA, M. M. O. A educação popular no campo: entre o saber camponês e o conhecimento científico. Rev. Ed. Popular, Uberlândia, v. 8, jan./dez. 2009.

SUERTEGARAY, D. M. A.; MORELLI, L. A. Arenização e monocultura do eucalipto no Sudoeste do Rio Grande do Sul. Revista Eletrônica da Associação dos Geógrafos Brasileiros, Seção Três Lagoas/MS, n. 14, ano 8, nov. 2011.

VIA CAMPESINA. Declaración soberania alimentaria. 1996. Disponível em: <www. viacampesina.org>. Acesso em: 4 nov. 2016.

Recebido em: 24/1/2017

Aceito em: 26/4/2017 